\title{
The effects of explosion on the musculoskeletal system
}

\author{
Arul Ramasamy ${ }^{1,2}$, Anna Hughes', Nicholas Carter' \\ and Jon Kendrew ${ }^{1,2}$
}

(3)SAGE

\begin{abstract}
Explosions remain the leading cause of death and injury to combatants in conflict. The current 'Global War on Terror' has resulted in a shift of explosive-related injuries from the battlefield into civilian centres. Despite musculoskeletal injuries being the most common injury witnessed in blast, there remains little research into the effects of blast on this system. In order to develop new treatment regimens and mitigation systems, there is a requirement to have a better understanding of skeletal trauma in this unique environment. The aim of this review article is to deconstruct the complex injury mechanisms witnessed in blast and relate them to its effects on the musculoskeletal system.
\end{abstract}

\section{Keywords}

Explosions, biomechanics, blast injury, fractures, soft tissue trauma, biophysics, musculoskeletal system

\section{Introduction}

In the past 100 years, explosive weapons have resulted in over $70 \%$ of all deaths and injuries to combatants in conflict (Boyd, 1975; Melsom et al., 1975; Palinkas and Cohen, 1985; Ramasamy et al., 2009b). Within this same period, a number of medical and logistical advances have resulted in an unprecedented rise in the survivability of battlefield injuries from $70 \%$ in World War II to $89 \%$ in Iraq (Mazurek and Ficke, 2006). These advances include improved body armour, enhanced prehospital care and timely aeromedical evacuation to surgical facilities capable of delivering optimised damage control resuscitative and surgical interventions. As a result, there has been an increased incidence of severely injured casualties surviving with multiple extremity injuries. In the current operational theatres of Iraq and Afghanistan, extremity injuries account for almost $70 \%$ of all combat wounds, of which approximately one third are fractures (Owens et al., 2007; Ramasamy et al., 2009a). However, these injury patterns are no longer restricted to the battlefield. The current 'Global War on Terror' has meant that the injuries once found

\footnotetext{
'Academic Department of Traumatology, Department of Trauma and Orthopaedics, Queen Elizabeth Hospital, Birmingham, UK

${ }^{2}$ Academic Department of Military Surgery and Trauma, Royal Centre for Defence Medicine, ICT Centre, Birmingham, UK

\section{Corresponding author:}

Arul Ramasamy, Academic Department of Military Surgery and Trauma, Royal Centre for Defence Medicine, ICT Centre, Birmingham Research Park, Vincent Drive, Birmingham BI5 2SQ, UK.

Email: a.ramasamy09@imperial.ac.uk
} 
exclusively in warfare can present in any major civilian centre. Frykberg and Tepas (1988) reported that $85 \%$ of terrorist bombing victims in Israel requiring surgery had soft tissue extremity injuries, with or without fractures.

Despite musculoskeletal trauma being the most common injury in military conflict and civilian terrorist activity, the study of blast pathophysiology has rarely focused on the musculoskeletal system and has concentrated on primary blast injuries of the pulmonary or central nervous systems (Bowen et al., 1968; Cooper et al., 1991; Hayda et al., 2004; Zuckerman, 1952), resulting in the development of improved protective measures and medical interventions. As a consequence, there exists a paucity of scientific investigation into the blast pathophysiology of the musculoskeletal system, fundamentally distinct from that described in blunt trauma research (Champion et al., 2009; Ramasamy et al., 2011). In order to drive the development of novel treatment and mitigation processes, it is incumbent upon clinicians, scientists and engineers to have a better understanding of the underlying injury mechanisms of extremity trauma. Therefore, the aim of this paper is to deconstruct the complex explosive injury process into its component parts and determine how they interact and disrupt the musculoskeletal system.

\section{The physics of blast}

When an explosive detonates, a shock wave is propagated through the explosive, causing an instantaneous $(<1 \mu \mathrm{s})$ chemical reaction. In the wake of this shock wave, the explosive is converted into a hot, high-pressure gas called the detonation products. Local pressures can exceed $35 \times 10^{6}$ psi (pounds per square inch), whilst temperatures range from 2000 to $6000^{\circ} \mathrm{C}$ (Baker, 1983). As the detonation products expand, forcing out the volume it occupies, a layer of compressed air (blast wave) forms in front of this gas volume. In an open-field explosive detonation, it is the blast wave that contains most of the energy released by the explosion.
There is an almost instantaneous rise in the pressure within the air surrounding the explosion, rapidly attaining its peak overpressure. As the blast wave travels through the air, the pressure wave dissipates in inverse proportion to the third power of the distance from the detonation point (Dewey, 1964). The detonation products then over-expand, leading to the development of a sub-atmospheric pressure phase. In this phase, a partial vacuum is created and air is sucked in. Turbulent movement of air following the blast wave cause debris to be thrown long distances away from the explosive source. The classical waveform (Friedlander wave) describes pressure changes at a fixed location relative to the explosive event in free field conditions (Friedlander, 1946).

The components of the blast wave that are responsible for the pathophysiological effects are the amplitude of the peak pressure, the impulse (the time integral of pressure) and the duration of the positive phase overpressure (Clemedson, 1956). Wakeley (1945) commented that a 'high peak overpressure is of little use if not sustained sufficiently long to distort the structure beyond its power of elastic recovery, and a large impulse is of little value if the pressure is less than the structure is able to withstand.' It has also been proposed that the dynamic overpressure of the detonation products (blast wind) and thermal energy released in the explosion contribute to blast injury (Cullis, 2001; Horrocks, 2001). Traditionally, blast injuries are classified according to the mechanism by which they are produced and these are summarised below (Zuckerman, 1952) (Table 1).

\section{Primary orthopaedic blast injury}

Primary orthopaedic blast injury is attributed to the effect of the blast-wave on skeletal structures. Blast waves, interacting with the body, will transfer energy at interfaces between tissues of differing acoustic impedance. This results in soft tissue injury and bone micro-fractures. Hull (1995) demonstrated that a goat limb, 
Table I. Blast injury classification and clinical manifestations in the musculoskeletal system. (Ramasamy et al., 20I0)

\begin{tabular}{|c|c|c|}
\hline Blast Injury & Mechanism of Injury & Clinical manifestations \\
\hline Primary blast effects & Blast shockwave & $\begin{array}{l}\text { Primary blast lung, gastrointestinal } \\
\text { injury, soft tissue deformation and } \\
\text { traumatic amputation. }\end{array}$ \\
\hline Secondary blast effects & $\begin{array}{l}\text { Fragments from explosive device } \\
\text { and energised debris }\end{array}$ & $\begin{array}{l}\text { Penetrating wounds to the extremities } \\
\text { resulting in significant soft tissue } \\
\text { injuries and fractures. }\end{array}$ \\
\hline $\begin{array}{l}\text { Combined primary and } \\
\text { secondary blast effects }\end{array}$ & $\begin{array}{l}\text { Combination of primary and } \\
\text { secondary injuries when } \\
\text { victim is near the seat of the } \\
\text { explosion. }\end{array}$ & $\begin{array}{l}\text { Massive soft tissue injury and sub-total } \\
\text { traumatic amputation of the limb. }\end{array}$ \\
\hline Tertiary blast effects & $\begin{array}{l}\text { Acceleration and deceleration } \\
\text { injuries to spine and extremi- } \\
\text { ties. } \\
\text { Crush phenomenon. }\end{array}$ & $\begin{array}{l}\text { Fractures from impact with solid } \\
\text { objects. Soft tissue injuries from } \\
\text { crush leading to compartment syn- } \\
\text { drome, nerve injury and crush } \\
\text { injuries. }\end{array}$ \\
\hline Quaternary blast effects & Thermal injuries and others & Burns \\
\hline
\end{tabular}

shielded from the effects of the detonation products and fragments, could be fractured by the blast wave alone when placed in close proximity to the seat of the explosion. Using a finite element modelling technique, he predicted that the blast wave will have reached the limb prior to any displacement of the limb from the detonation products. If the blast wave entered the tibia from the side, the bending forces exerted by the blast wave combined with the geometry of the tibia and the differential movement afforded by the knee and ankle joints result in the peak stresses being situated within the upper third of the tibia. The resulting axial and shear forces exceed the failure stress of bone, leading to fracture (Figure 2). This is echoed in clinical experience, where the proximal third of the tibia is the most common site for traumatic amputation in these circumstances (Hull and Cooper, 1996).

Once the bone has fractured, the detonation products expose the bone to significant bending stresses. Hull (1992) suggested that these stresses, occurring at the site of the blast-waveinduced fracture, is the likely mechanism of traumatic amputation. Clinically this manifests as a traumatic amputation, with the proximal stump containing short oblique or transverse fracture morphology (Figure 2(b)).

\section{Primary blast effects on soft tissues}

Little is known about how the cellular and molecular properties of skeletal tissue are altered in response to shock waves at magnitudes that correspond to conditions that would result in a blast injury. However, there is a considerable body of literature on the use of low energy shock waves in extracorporeal shock wave therapy (ESWT) in orthopaedic applications (see reviews by McClure et al., 2004; Zelle et al., 2010), but the magnitude of therapeutic shock waves is reduced by approximately six orders of magnitude (Ogden et al., 2001). A range of biological changes have been observed at a molecular level using animal models and cells that indicate a key effect of ESWT is to stimulate osteogenesis through signalling processes and/ or growth factor production (Zelle et al., 2010). For example, studies of human osteoblasts stimulated with therapeutic-level shock waves demonstrated alterations in the regulation 
of genes involved in cellular proliferation and differentiation (Hofmann et al., 2008). Increasing the energy above treatment thresholds, but still many orders of magnitude below

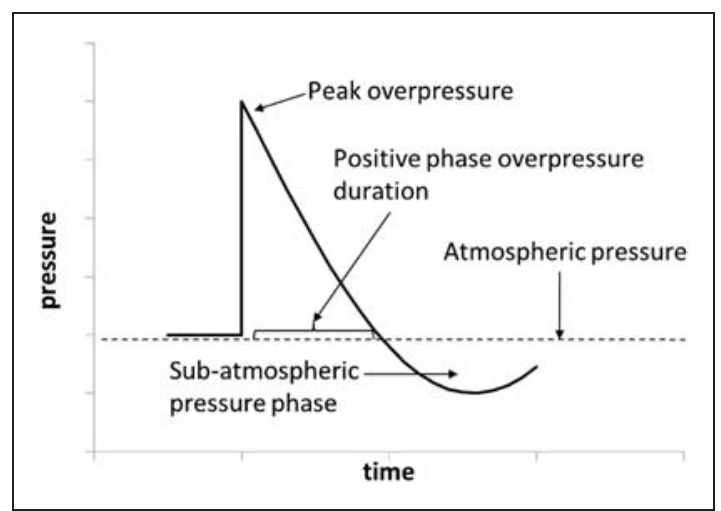

Figure I. Blast overpressure plot depicting an idealized free field explosion; adapted from Friedlander (1946). blast conditions, can result in bone fractures with accompanying damage to periosteal soft tissue and the bone marrow cavity (Maier et al., 2002; Valchanou and Michailov, 1991). Damage to vascular and nerve tissues are amongst the known complications associated with ESWT (McClure et al., 2004). The molecular basis for this damage, however, remains largely uncharacterised.

\section{Secondary orthopaedic blast injury}

Secondary blast injury is caused by penetrating trauma from bomb casing fragments, materials implanted within the explosive, or from debris energised by proximity to the explosion. These fragments can cause bone fracture either directly or indirectly. Direct impact of a high-energy fragment into bone typically results in a highly comminuted fracture. Often these bone fragments have no periosteal attachment and thus

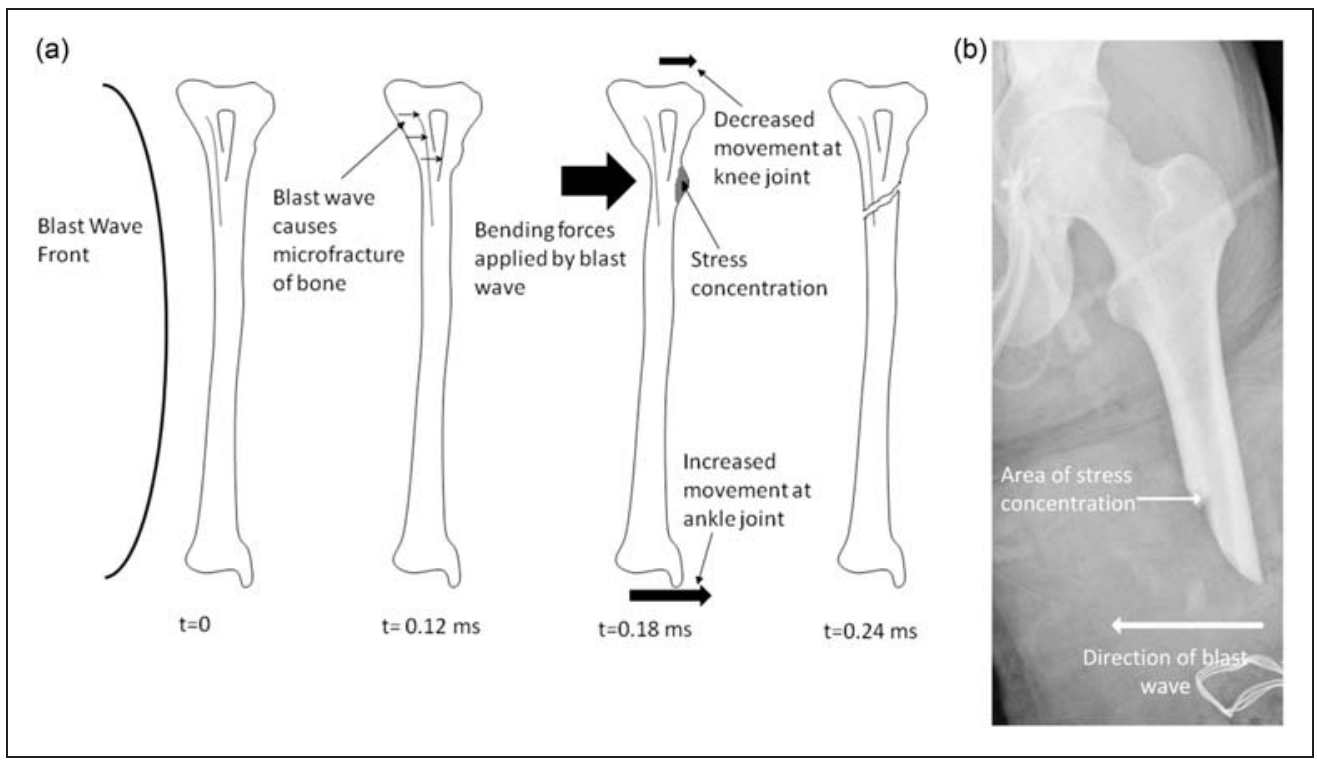

Figure 2. (a) The blast wave interacts with the tibia causing micro-fracture within the bone. Due to the bone geometry and the differential movement allowed by the knee and ankle joint, the bending forces exerted on the tibia by the blast wave, results in an area of stress concentration. The peak hoop and axial stresses within this area exceeds the tensile failure stress of bone, resulting in fracture; adapted from Hull (1995). (b) A traumatic amputation of the femur. Note the absence of significant soft tissue disruption or fragments and the short oblique fracture pattern of the stump. 
no blood supply. Additionally, these highenergy transfer wounds produce significant contamination of the fracture site and the medullary canal. Both of these effects increase the risk of developing long-term infective complications. This has been reflected in military studies, where Brown et al. (2010) reported a $24 \%$ infection rate in a review of 85 long bone fractures caused by ballistic trauma.

If the fragment is travelling at a slower velocity, full penetration of the bone does not occur and only a single cortex is breached. In these cases, the classical 'drill-hole' fracture is produced. Clinically, these injuries have a good clinical prognosis and do not require operative fracture stabilisation. Rose et al. (1988) reported 12 cases of drill hole fractures of the femur treated conservatively with no complications.

Indirect fractures can be caused by a highenergy fragment passing in close proximity to bone (Callender and French, 1935). Such injuries are caused by the high pressures exerted on the bone surface by the leading edge of the rapidly expanding temporary cavity (McMillen, 1945). The fractures show no bone loss and the fragments retain periosteal attachments and are therefore likely to remain viable. The fracture configurations in these injuries are usually simple (i.e. transverse or oblique) with little comminution.

\section{Secondary blast effects on soft tissues}

As the fragment passes through soft tissue, damage is caused directly to those tissues in the direct path of that fragment. In addition, a high-pressure compression wave is generated radially, creating a temporary cavity. This rapidly expanding cavity forms a subatmospheric pressure, which draws in external debris from both the entry and exit wounds, increasing the risk of wound contamination from foreign bodies. The temporary cavity oscillates, leaving behind a smaller permanent cavity formed by the fragment's trajectory through the tissue (Figure 3).

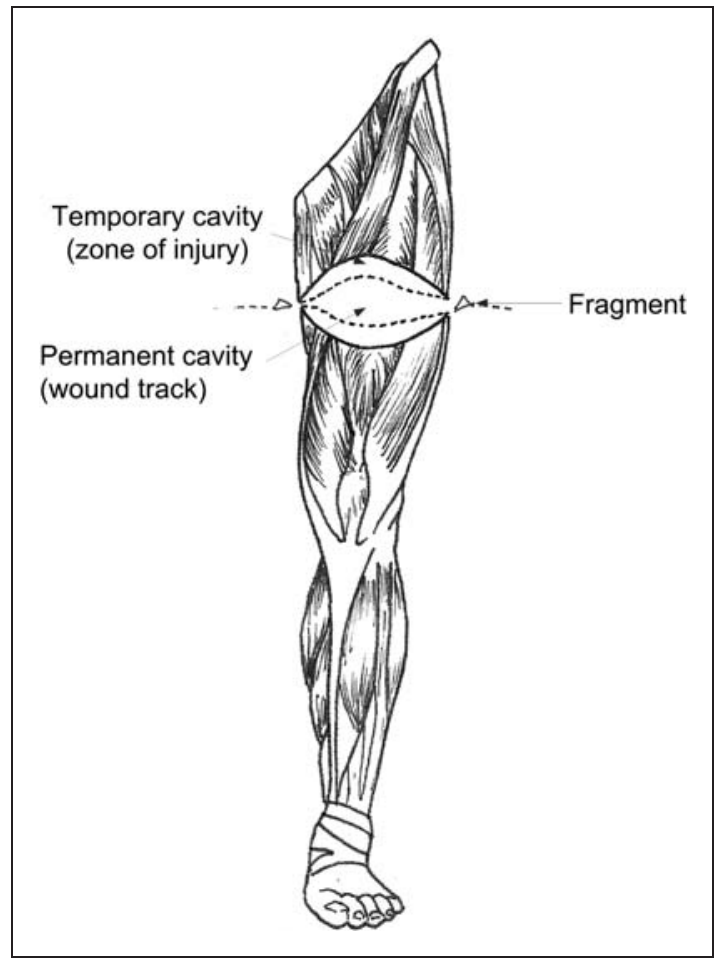

Figure 3. As the fragment passes through the soft tissue, a permanent cavity is formed by direct damage to the tissues that lay in its path. In the wake of the fragment, a rapidly expanding radial compressive wave results in a sub-atmospheric temporary cavity that not only forms a zone of injury but also sucks in foreign debris through the entry and exit wounds. Hence, the zone of injured, contaminated tissue may be far greater than the permanent wound track formed by the projectile itself.

The sizes of the temporary and permanent cavities are determined by the kinetic energy, size and shape of the causative fragment and the nature of the tissue through which it passes (Clasper, 2001). Blast fragments travelling with high velocity and kinetic energy lead to a large temporary cavity and the area of devitalised tissue around the permanent cavity/fragment trajectory can extend up to several centimetres. The zone of soft tissue injury is subsequently much greater than the remaining wound tract. Additionally, the irregular nature of the penetrating surface of shrapnel in comparison with 
a stable bullet will lead to a greater transfer of kinetic energy to the surrounding tissues along its course, thereby causing greater damage (Liu et al., 1988). Muscle and skin have high elastic potentials and can therefore tolerate higher kinetic forces than less elastic tissues such as the liver (Ryan et al., 1997). As a consequence, simple surgical debridement of the wound track may not be sufficient to remove nonviable tissue that may have been injured when the temporary cavity was formed. Hence, it is essential that the operating surgeon is aware for the potential of a large zone of injury adjacent to the tract formed by a particular fragment.

Blast injuries invariably do not involve one single fragment and with multiple high energy penetrating injuries, multiple cavities form and there will be a large degree of soft tissue damage. It is therefore not surprising that soft tissue injuries form the greatest proportion of serious battle wounds (Bellamy and Vayer, 1988).

Peripheral nerves, in close proximity to the trajectory of fragments, are remarkably resistant to injury (Stapley and Cannon, 2006). Due to the highly elastic properties of nervous tissue, nerves that lie within the temporary cavity formed by the passing fragment are able to withstand the transfer of kinetic energy, and thus are rarely entirely disrupted (Mitchiner, 1939). Contusion or neuropraxia can result, which is demonstrated clinically with partial or complete conduction block at the lesion; this has a good outcome as it is a transient paralysis (Campbell, 2008). However, if the nerve falls directly in the trajectory of the passing fragment, complete disruption is then possible. This is referred to as neurotmesis (literally meaning 'cutting of the nerve') (Seddon, 1942). Rather than the two ends of the nerve appearing cleanly divided, they are often ragged and bruised. Neurotmesis has a poor outcome as there is complete paralysis of the nerve and the previously innervated muscles atrophy.

Whilst the macroscopic neurotmesis lesions are rare, the kinetic energy transferred from the passing fragment does have a detrimental effect on the nerves on an intra- and intercellular level. Sunesan et al. (1987) demonstrated that when pigs were shot with a high-energy missile in the hindlimb, damage to the blood-brain and blood-nerve barriers occurred far distant from the site of impact. It was even found that there was a decrease in the number of microtubules and damage to the myelin sheaths of the sciatic nerve of the leg on the contralateral side to that which had been injured (Sunesan et al., 1990).

\section{Mixed primary and secondary orthopaedic blast injury}

If the victim is situated close to the seat of the explosion, the effects of the blast wave and detonation products occurs almost instantaneously. This effect is classically noted following the detonation of an anti-personnel mine. Upon detonation, the blast wave is transmitted directly into the limb, resulting in a brisance effect on bone. One or two milliseconds post-detonation, the detonation products and casing/environmental fragments contact the limb causing destruction of traumatised soft tissue and applying maximal stresses on bone previously damaged by the blast wave (Nechaev et al., 1994; Trimble and Clasper, 2001). The net result is either a total or sub-total amputation of the limb, with the zone of soft tissue injury (including significant amounts of foreign debris and fragments) extending more proximally than the damaged bone.

\section{Mixed primary and secondary effects on soft tissues}

Based on histological studies of combat casualties during the Soviet occupation of Afghanistan and animal models, Nechaev et al. (1994) described 3 major zones of injury following a mine blast (Figure 4).

Zone I represented the area closest to the seat of the explosion. It was characterised by traumatic amputation of the limb, with widespread damage and anatomical destruction at different 


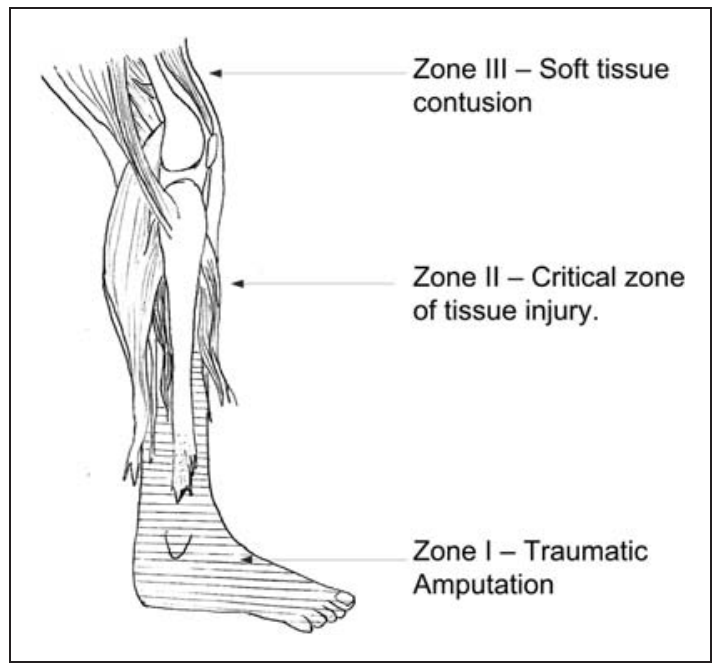

Figure 4. The zones of injury following a mine explosion.

levels of the skin, tendons, muscles, bones and neurovascular structures. In all cases, the soft tissue injuries within this zone are associated with significant contamination from soil and energised explosive fragments. A particular feature of these injuries included disruption of tissues along fascial sheaths with the high-pressure detonation gases driving soil proximal to the level of bone traumatic amputation. Based on the level of local soft tissue injury, surgical amputations performed through Zone I was considered non-viable.

Within Zone II of the injured limb, there are focal areas of micro-laceration of the muscle fascicles with associated lacerations of small and large blood vessels, giving rise to focal areas of haemorrhage. From arteriograms performed in animal studies, it was determined that there remained a persistent impairment of blood flow in this zone, with segmental vasospasm and dilatation of arterioles and venules a consistent feature. In addition, endoneural and epineural haemorrhage was witnessed within the peripheral nerves with associated oedema of the nerve. The level of injury diminished with increasing distance from the Zone I boundary, with areas of tissue completely undamaged. Of note, the focal areas of injuries appeared to be localised near the neurovascular bundles and the osteofascial planes, suggestive of transmission of the blast wave through these structures.

The main features of injuries in Zone III are avulsion of small arterioles from main vessels, impaired venous return and reactive changes in the axons of peripheral nerves. In a review of 19 casualties who underwent serial biopsies following surgical amputation in Zone III and made an uncomplicated recovery from their injuries, it was noted that in the first 5 days, there remained extensive tissue oedema with pronounced marginal necrosis of the muscle boundary. This was associated with demyelination of the peripheral nerves. From days 6 to 14, it was noted that vessels in the amputation stump showed signs of panvasculitis with further necrosis of muscle fibres. In addition, biopsy of the peripheral nerves revealed hyperplasia of the Schwann cells and the formation of traumatic neuromas and neurofibromas.

Based on these findings, Nechaev et al. (1994) recommended that the optimal level for surgical amputation should be at the border of Zones II and III. Clinically this manifests as the ability for muscle fibres to contract and minimal soft tissue oedema.

\section{Tertiary blast injury}

Tertiary orthopaedic blast injuries occur as a result of bodily displacement of the casualty or impact against solid structures (Bowen et al., 1961). As such the injuries witnessed bear similar characteristics to those seen in civilian blunt trauma. When bone is subjected to external loads, local instabilities arise from osseous imperfections. This results in the nucleation, multiplication and growth of micro-cracks, their localization in certain areas and finally the formation of a macroscopic fissure (fracture) due to the coalescence of localised micro-cracks in the most densely damaged area (Zioupos et al., 2008). The pattern of the resulting fracture is a function of the direction and intensity of the 


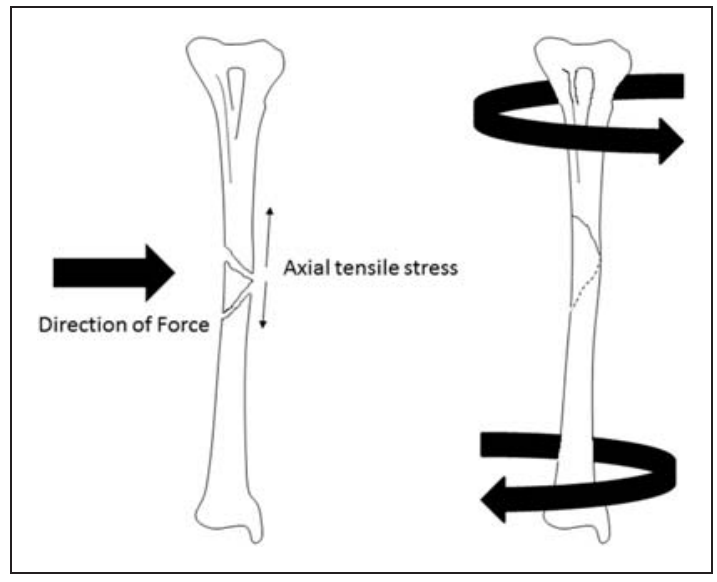

Figure 5. The influence of load application on fracture pattern. A direct force applied perpendicular to the long axis of the tibia results most commonly in a tension wedge fracture with the apex formed at the opposite cortex to force application. In order to produce a spiral fracture, a torsional load must be applied to the bone.

load applied, the geometry of the bone injured and the subject- and location-specific material properties.

Kress et al. (1995) reported the results of long bone fractures induced by impacting whole limbs using a pneumatically driven impactor. They reported that with loads applied perpendicular to the axis of the bone, the most common fracture reported was a tension wedge (Figure 5) and that this did not change with the direction of the impact. Tensile wedge fractures originate at a location directly opposite the point of impact and the wedge segment radiates back through the bone initially forming a $90^{\circ}$ vertex angle. This suggest failure due to direct stress, i.e. axial loading of the bone in tension at the far cortex (Benham and Crawford, 1987). They also noted that the level of comminution at the fracture site was related to increasing speed of impact. Spiral fractures only appeared when the bones were subjected to additional torsional loads and that these fractures occurred $100 \%$ of the time when a pure torsional load was applied (Figure 5), implying that failure was due to shear stress.

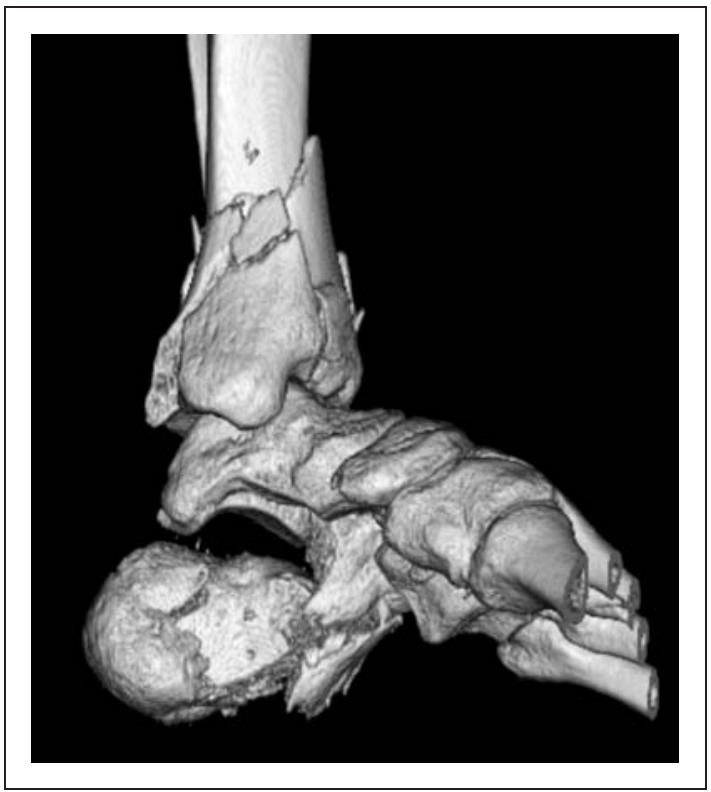

Figure 6. A CT reconstruction of a comminuted calcaneal fracture sustained from an underground explosion.

Severe axial loading of the lower limbs can occur if the casualties land on their feet after being thrown by the explosion or as a direct result of the upwards blast of an explosive device. The usual injury pattern being the comminuted distal tibial 'Pilon' type fracture with an ipsilateral, open, comminuted intra-articular calcaneal fracture; a pattern of injury similar to civilian injuries sustained by falls from significant heights (Galloway and Zephro, 2007; Scalea et al., 1986) (Figure 6).

\section{Tertiary blast effects on soft tissues}

The sudden displacement of casualties by the blast wind can result in severe soft tissue injury from both crush injuries by impacting solid objects and also significant injury secondary to fractures. One of its most significant effects is the development of compartment syndrome. Compartment syndrome is a limb-threatening condition observed when perfusion pressure falls below intracompartmental pressure in a 
closed osteofascial space. Bleeding, oedema or inflammation may increase the pressure within one of the osteofascial compartments. This leads to decreased capillary flow, which results in ischaemia, oedema and further increase in the pressure of the compartment. A vicious cycle occurs that ultimately leads to the necrosis of the nerves and muscles within the compartment within $12 \mathrm{~h}$ (Holden, 1979). Once infarcted, the muscles are replaced by inelastic fibrous tissue (Volkmann's ischaemic contracture), leading to significant morbidity.

Explosions can cause fracture, tissue loss and vascular injury, all of which place the extremities at risk of developing compartment syndrome. A number of factors may prevent prompt diagnosis of the condition; namely, multiple casualties from a single explosive event may reduce the opportunity for serial examinations, casualties suffering multiple distracting injuries, analgesics, sedation, oedema formation or delayed bleeding into compartments following adequate resuscitation, and application of constrictive splints.

This has been demonstrated in a study of fasciotomies performed in US combat casualties. Ritenour et al. noted that out of 332 patients undergoing fasciotomies, $17 \%$ required a revision procedure, resulting in higher rates of muscle excision (35\% vs $9 \%)$ and mortality $(20 \%$ vs $6 \%)$. Those casualties who received fasciotomies after evacuation, amputation rates were twice those who had fasciotomies in theatre ( $31 \%$ vs $15 \%$ ). The most commonly unopened compartments were the anterior and deep posterior compartment of the lower leg (Ritenour et al., 2008). The authors concluded that there was a need for increased vigilance for compartment syndrome in severely injured patients and they urged the early use of complete fasciotomies and prophylactic fasciotomies in highrisk patients.

If the casualty is driven against a solid object or is trapped under falling debris, crush injuries can occur. The extent of the muscle injury depends both on the magnitude of the force and the length of time the force is applied.
Prolonged crush injuries results in muscle ischaemia, with muscle death occurring after $6 \mathrm{~h}$. If the crushing force is applied for less than $6 \mathrm{~h}$, the damage is a direct result of the mechanical crushing force (Reis and Michaelson, 1986). On a cellular level, increased stress on the sarcolemma membrane results in leakage, leading to ingress of Sodium and Calcium into the sarcoplasm. This then traps extracellular fluid inside the myocytes. Simultaneously, Potassium, Phosphate, Myoglobin and Urate leak from the myocytes with potentially toxic systemic effects (Greaves et al., 2004; Jagodzinski et al., 2010). This may then progress to crush syndrome, a reperfusion injury as a result of traumatic rhabdomyolysis, which can, in extreme circumstances, lead to renal failure and the need for dialysis. Bywaters and Beall's (1941) description of rhabdomyolysis during World War II provided the first causal relationship between acute renal failure and rhabdomyolysis.

In addition to muscle injury, nerve injury can also occur as a result of tertiary blast effects. Within the spectrum of crush injuries, persistent compression of nerves can lead to a mini-compartment syndrome within the endoneurium, causing nerve ischaemia and irreversible nerve injury (Lundborg et al., 1983). Nerve injury may also occur as a result of stretching following fracture. Wall et al. (1991) demonstrated that if nerves are subjected to strain rates exceeding $12 \%$, irreversible nerve injury occurred.

\section{Conclusions}

Explosions are a complex physical phenomenon that interact and cause physiological dysfunction of the skeletal system through a number of different mechanisms. Deconstructing this phenomenon into its component pathways is fundamental to understanding the effect of blast on the musculoskeletal system. The development of future mitigation and novel therapeutic interventions will require a multi-scalar approach in understanding these effects on a cellular, tissue and organ level. 


\section{Funding}

This research received no specific grant from any funding agency in the public, commercial, or notfor-profit sectors.

\section{Conflicts of interest}

This research received no specific grant from any funding agency in the public, commercial, or not-for-profit sectors. The authors declare that they have no conflicts of interest in respect to this manuscript.

\section{References}

Baker W (1983) Explosion Hazards and Evaluation. Amsterdam, Netherlands: Elsevier.

Bellamy RF and Vayer JS (1988) Assessment of penetrating injury severity. In: Maull KI, Cleveland $\mathrm{HC}$, Strauch GO, et al. (eds) Advances in Trauma. Chicago, IL: Year Book Publishers Inc.

Benham PP and Crawford RJ (1987) Mechanics of Engineering Materials. Harlow, UK: Longman Scientific \& Technical.

Bowen IG, Albright RW, Fletcher ER, et al. (1961) CEX-58.9 A Model Designed to Predict the Motion of Objects Translated by Classical Blast Waves. Oak Ridge, TN: Department of Commerce.

Bowen IG, Fletcher ER and Richmond DR (1968) Estimate of Man's Tolerance to the Direct Effects of Air Blast. Washington DC: Headquarters Defence Atomic Support Agency.

Boyd NA (1975) A military surgical team in Belfast. Ann $R$ Coll Surg Engl 56: 15-25.

Brown KV, Murray CK and Clasper JC (2010) Infectious complications of combat-related mangled extremity injuries in the British Military. J Trauma 69: S109-S115.

Bywaters EGL and Beall D (1941) Crush injuries with impairment of renal function. BMJ 1: 427-432.

Callender GR and French RW (1935) Wound ballistics: Studies in the mechanism of wound production by rifle bullets. Milit Surg 77: 177-201.

Campbell WW (2008) Evaluation and management of peripheral nerve injury. Clin Neurophysiol 119: 1951-1965.

Champion HR, Holcomb JB and Young LA (2009) Injuries from explosions: physics, biophysics, pathology and required research focus. J Trauma 66: 1468-1477.
Clasper JC (2001) The interaction of projectiles with tissues and the management of ballistic fractures. J R Army Med Corps 147: 52-61.

Clemedson C-J (1956) Blast injury. Physiol Rev 36: 336-354.

Cooper GJ, Townend DJ, Cater SR, et al. (1991) The role of stress waves in thoracic visceral injury from blast loading: modification of stress transmission by foams and high-density materials. J Biomech 24: 273-285.

Cullis IG (2001) Blast waves and how they interact with structures. J R Army Med Corps 147: 16-26.

Dewey JM (1964) The air velocity in blast waves from TNT explosions. Proc $R$ Soc Lond A 279: 366-385.

Friedlander FG (1946) The diffraction of sound pulses. I. Diffraction by a semi-infinite plane. Proc $R$ Soc Lond A 186: 322-344.

Frykberg ER and Tepas III JJ (1988) Terrorist bombings. lessons learned from Belfast to Beirut. Ann Surg 208: 569.

Greaves I, Porter K and Smith JE (2004) Consensus statement on the early management of crush injury and prevention of crush syndrome. J R Army Med Corps 150: 102-106.

Hayda R, Harris RM and Bass CD (2004) Blast injury research. Clin Orthop Rel Res 422: 97-108.

Hofmann A, Ritz U, Hessmann MH, et al. (2008) Extracorporeal shock wave-mediated changes in proliferation, differentiation, and gene expression of human osteoblasts. J Trauma 65: 1402-1410.

Holden CE (1979) The pathophysiology and prevention of Volkmann's ischaemic contracture. J Bone Joint Surg Br 61: 296-300.

Horrocks CL (2001) Blast injuries: Biophysics, pathophysiology and management principles. J R Army Med Corps 147: 28-40.

Hull JB (1992) Traumatic amputation by explosive blast: Pattern of injury in survivors. BJS 79: 1303-1306.

Hull JB (1995) An investigation into the mechanism of traumatic amputation by explosive blast. Doctor of Medicine, University of Birmingham.

Hull JB and Cooper GJ (1996) Pattern and mechanism of traumatic amputation by explosive blast. J Trauma 40: S198-S205.

Jagodzinski NA, Weerasinghe C and Porter K (2010) Crush injuries and crush injuries - a review. Trauma 12: 133-148.

Kress TA, Porta DJ, Snider JN, et al. (1995) Fracture patterns of human cadaver long bones. IRCOBI. Brunnen: IRCOBI. 
Liu Y, Chen X, Chen SLX, et al. (1988) Wounding effects of small fragments of different shapes at different velocities on soft tissues of dogs. J Trauma 28: S95-S98.

Lundborg G, Myers R and Powell H (1983) Nerve compression injury and increased endoneurial pressure: a "miniature compartment syndrome". J Neurol Neurosurg Psychiatry 46: 1119-1124.

Maier M, Milz S, Tischer T, et al. (2002) Influence of extracorporeal shock-wave application on normal bone in an animal model in vivo: Scintigraphy, MRI and histopathology. J Bone Joint Surg [Br] 84-B: 592-599.

Mazurek MT and Ficke JR (2006) The scope of wounds encountered in casualties from the Global War on Terrorism: from the battlefield to the tertiary treatment facility. J Am Acad Orthop Surg 14: S18-S23.

McClure SR, Van Sickle D and White MR (2004) Effects of extracorporeal shock wave therapy on bone. Vet Surg 33: 40-48.

McMillen JH (1945) Shock wave pressures in water produced by impact of small spheres. Phys Rev 68: 198-209.

Melsom MA, Farrar MD and Volkers RC (1975) Battle casualties. Ann $R$ Coll Surg Engl 56: 289-303.

Mitchiner PH (1939) Wounds of the peripheral nerves and blood vessels. BMJ 2: 124-126.

Nechaev EA, Gritsanov AI, Fomin NF, et al. (1994) Mine Blast Trauma. St Petersberg, Russia: Russian Federation Ministry of Public Health and Medical Industry.

Ogden JA, Alvarez RG, Levitt R, et al. (2001) Shock wave therapy (Orthotripsy (R)) in musculoskeletal disorders. Clin Orthop Relat Res 387: $22-40$.

Owens BD, Kragh Jr JF, Macaitis J, et al. (2007) Characterization of extremity wounds in Operation Iraqi Freedom and Operation Enduring Freedom. J Orthop Trauma 21: 254-257.

Palinkas LA and Cohen P (1985) Combat casualties among US Marine Corps personnel in Vietnam: 1964-1972. San Diego, CA, USA: Naval Health Research Centre.

Ramasamy A, Harrisson S, Lasrado I, et al. (2009a) A review of casualties during the Iraqi insurgency 2006-a British field hospital experience. Injury 40: 493-497.

Ramasamy A, Harrisson SE, Stewart MP, et al. (2009b) Penetrating missile injuries during the
Iraqi insurgency. Ann $R$ Coll Surg Engl 91: 551-558.

Ramasamy A, Hill AM, Masouros SD, et al. (2010) Blast-related fracture patterns: a forensic biomechanical approach. J R Soc Interface 8: 689-698.

Ramasamy A, Masouros SD, Newell N, et al. (2011) In-vehicle extremity injuries from improvised explosive devices: current and future foci. Phil $T$ Roy Soc B 366: 160-170.

Reis ND and Michaelson M (1986) Crush injury to the lower limbs. Treatment of the local injury. J Bone Joint Surg Am 68: 414-418.

Ritenour AE, Dorlac WC, Fang R, et al. (2008) Complications after fasciotomy revision and delayed compartment release in combat patients. J Trauma 64: S153-S162.

Rose SC, Fujisaki CK and Moore EE (1988) Incomplete fractures associated with penetrating trauma: etiology, appearance and natural history. J Trauma 28: 106-109.

Ryan JM, Rich NM and Ochsner MG (1997) Biophysics and pathophysiology of penetrating trauma. In: Ryan JM, Rich NM, Dale RF, et al. (eds) Ballistic Trauma. London: Arnold.

Seddon HC (1942) A classification of nerve injuries. BMJ 2: 237-239.

Stapley SA and Cannon LB (2006) An overview of the pathophysiology of gunshot and blast injury with resuscitation guidelines. Current Orthopaedics 20: 322-332.

Sunesan A, Hansen HA and Seeman T (1987) Peripheral high-energy missile hits cause pressure changes and damage to the nervous system: experimental studies on pigs. $J$ Trauma 27: $782-789$.

Sunesan A, Hansen HA and Seeman T (1990) Pressure wave injuries to the nervous system caused by high-energy missile extremity impact: Part I. Local and distant effects on the peripheral nervous system - a light and electron microscopy study on pigs. J Trauma 30: 281-294.

Trimble K and Clasper JC (2001) Anti-personnel mine injury; mechanism and medical management. J R Army Med Corps 147: 73-79.

Valchanou VD and Michailov P (1991) High energy shock waves in the treatment of delayed and nonunion of fractures. Int Orthop 15: 181-184.

Wakeley CPG (1945) Effect of underwater explosion on the human body. Lancet 245: 715-718.

Wall EJ, Massie JB, Kwan MK, et al. (1991) Experimental stretch neuropathy changes in 
nerve conduction under tension. J Hand Surg 16: 859-863.

Zelle BA, Gollwitzer H, Zlowodzki M, et al. (2010) Extracorporeal shock wave therapy: Current evidence. J Orthop Trauma 24: S66-S70.

Zioupos P, Hansen U and Currey JD (2008) Microcracking damage and the fracture process in relation to strain rate in human cortical bone tensile failure. J Biomech 41: 2932-2939.

Zuckerman S (1952) Vulnerability of human targets to fragmenting and blast weapons. In: Zuckerman $\mathrm{S}$ (ed.) Textbook of Air Armament. London, UK: HMSO, pp. 1-243. 